\title{
Role of Input Selection Prediction of Physical Properties of Degradable Composites Using ANFIS
}

\author{
Syamsiah Abu Bakar, Rosma Mohd Dom, Ajab Bai Akbarally, and Wan Hasamudin Wan Hassan
}

\begin{abstract}
ANFIS employ multi-input single-output (MISO) system. This paper proposes role of input selection using neuro-fuzzy approach for the prediction of physical properties of degradable composites namely melt flow index and density. Experiments on the physical properties of degradable composites are currently carried out in the laboratories of Malaysian Palm Oil Board. ANFIS simulation provides good alternative method for minimize the time consumed, the cost of production and the cost of labour on the production of degradable composites. The results reveal that, all the input selection give high prediction accuracy by smallest Root Mean Square Error (RMSE) values and high correlation coefficient $(R)$, coefficient of determination $\left(R^{2}\right)$ and adjusted $\mathbf{R}$ square $\left(\bar{R}^{2}\right)$. These findings give additional evidence that ANFIS has high ability on input selection in the prediction of degradable composites.
\end{abstract}

Index Terms-ANFIS, degradable composites, input selection, physical properties.

\section{INTRODUCTION}

The need in modeling properties of fibre reinforced polymer composites is important in order to minimize cost and time consumed. In practice, it has been found that, the traditional equations derived for the solutions of real life problems are not suitable for modeling non-linearity and also to deal with imprecise and uncertain findings [1]. Therefore, a technique namely soft computing is an alternative method for solving the real life problems [2]. Overall, an Adaptive Neuro-Fuzzy Inference System (ANFIS) is one of the soft computing methods which has been proved to give high accuracy in the prediction of properties of fibre reinforced polymer composites [3]. ANFIS is a combination of Fuzzy Logic and Neural networks. By the hybridization of these two models, ANFIS has good learning capabilities and easy interpretability [2]. ANFIS utilize the concept of multilayer feed-forward network which uses fuzzy reasoning to map input into an output and neural network learning algorithms [4]. ANFIS architecture is employed to model nonlinear

Manuscript received December 2, 2014; revised March 25, 2014. The work presented in this paper is supported by University Technology MARA and Malaysia Ministry of Science, Technology and Innovation with the Grant 600-RMI/ST/FRGS 5/3/Fst (79/2010).

Syamsiah Abu Bakar is with the University Kuala Lumpur Malaysia France Institute, Malaysia (e-mail: syamsiah@unikl.edu.my).

Rosma Mohd Dom and Ajab Bai Akbarally are with the Universiti Technology Mara, Malaysia (e-mail: rosma@tmsk.uitm.edu.my, ajab@tmsk.uitm.edu.my).

Wan Hasamudin Wan Hassan is with the Biomass Technology Centre, Engineering \& Processing Division, MPOB, Malaysia (e-mail: wanhaswh@mpob.gov.my). functions, identify nonlinear components on-lineally in control systems and predict a chaotic time series [5].

\section{A. Adaptive Neuro-Fuzzy Inference System (ANFIS)}

Fuzzy set theory was introduced by Zadeh in 1965 to deal with vague, imprecise and uncertain problems. Fuzzy set is the extension of the classical set or known as the crisp set [6]. In a crisp set, a value can only be completely true or completely false [7]. On the other hand, fuzzy set is based on the concept of membership in which an element can be a member of the set with some membership value.

Fuzzy Logic (FL) is an application area of fuzzy set theory [8]. FL approach is based on the linguistic uncertainty expression rather than numerical uncertainty. FL consists of 4 basic components; fuzzification, fuzzy rule base, fuzzy output engine and defuzzification [9]. According to [10], FL is new in polymer research area. Since the development of FL in polymer is still in its basic stages, [11] recommended the application of FL in future researches.

On the other hand, Neural Networks (NN) is a data-driven black-box method for solving highly non-linear complex problems because NN can learn from examples [12]. NN model uses training data set to modify its weights of all connecting nodes until the desired level of error is achieved. Testing data set is then used to evaluate the network performance. Predictive quality is tested by RMSE of the testing data set. The smaller RMSE indicates better predictive ability [12].

In order to get a specific target input, a suitable learning algorithm such as supervised learning, un-supervised learning or incremental learning is used, so that a particular input leads to a specific target output [6]. However, the knowledge is stored in an opaque fashion which is lacking the interpretative answers [13].

NN and FL have attracted growing interest from researchers in various scientific and engineering areas due to the growing need of adaptive intelligent systems to solve real world problems [11]. In order to have good learning capabilities and easy interpretability, both models were hybridized [2]. The hybrid model, specifically called ANFIS is a powerful new soft computing model approach proposed by Jang in 1993 [14].

ANFIS is a fuzzy inference system (FIS) implemented in the framework of NN and its architecture and functionality are equivalent to a Sugeno type fuzzy rule base. ANFIS employs the concept of multilayer feed- forward network which uses fuzzy reasoning to map inputs into an output and NN learning algorithms [15]. ANFIS can be used to model nonlinear functions, identify nonlinear components in control systems and predict a chaotic time series, all yielding remarkable results [5]. 


\section{B. Studies of Degradable Composites}

Natural fibre reinforced in polymers has been studied widely by academics and industrial researchers around the world. The studies include investigation of mechanical and physical properties of degradable composites, thermal behaviour, the effects of treated fibres and untreated fibres.

Numerous mathematical modeling have been applied in the study of natural fibre reinforced polymer composites. These studies include ANFIS model, Regression model, modified rule of mixtures (ROM) strength, simple ROM strength, micromechanical model, Tobias and Y. Agari models. However, the majority of these studies were mainly based on laboratories observations which did not apply any modeling concepts.

The use of Fuzzy Logic and neuro-fuzzy in modeling the mechanical properties of composites was employed by [16] to study the fatigue life of unidirectional glass fibres/ epoxy composites. [16] used the ANFIS model developed based on the first-order Sugeno fuzzy model. A hybrid learning algorithm is used in order to train the data set. The selection of inputs used in their study was based on the work done by [17]. The interesting part about their study was the investigation on the influence of different membership functions (Triangular-shaped, Gaussian and Bell-shaped) and the number of linguistic values. In comparison between membership functions, [16] indicated that the ANFIS model with the Bell-shaped membership function gave a higher accuracy in the prediction of fatigue life. The performance results of the ANFIS model by [16] are compared with the ANN model by [17]. It is found that the ANFIS model with the hybrid neuro-fuzzy method performed better than ANN.

This study is attempted to investigate role of input selection using ANFIS model in prediction of physical properties of degradable composites namely melt flow index and density. Input selection is important to remove irrelevant inputs and also inputs that depend on other input [18]. This will be minimize the time needed to construct a model. Therefore, it is necessary to choose relevant inputs in constructing a model. Exemplary studies on input selections are input selection for nonlinear regression using fuzzy clustering approach [19], input selection for ANFIS learning [18] and selecting input variables for fuzzy models [20].

This study is motivated by the environmental problems caused directly or indirectly by the production and use of plastics in the industry due to the lack of knowledge concerning the environment and consumers' behavior. Identifying the suitable amount of composition of polyethylene with other gelling agents and filler in the production of degradable composites is essential in producing environmental friendly plastics as well as alternative way for researchers obtain more reliable and understandable result.

This paper presents the first account on:

1) To develop ANFIS simulation model that can be determine which of the suitable components of degradable composites namely; oil palm biomass (OPB), polyethylene (PE), palm oil (PO) or starch and give the highest impact on the melt flow index and density of degradable composites.

2) To assess the performance of ANFIS model in the prediction of the MFI and density of degradable composites.

\section{MeTHODOLOGY}

\section{A. Data Sets}

This research uses data obtained from the Malaysian Palm Oil Board (MPOB). The inputs are Oil Palm Biomass (OPB) $(\%)$, Polyethylene (PE) (\%), Palm Oil (PO) (\%) and starch $(\%)$. The outputs are the physical properties of degradable composites namely melt flow index (g/10min) and density $\left(\mathrm{g} / \mathrm{cm}^{3}\right)$. The sample set obtained from MPOB laboratories is very small to be applied in the ANFIS model. Thus, the data set was bootstraped for 10 times since according to [21], the bigger the data set, the more accurate the prediction is.

\section{B. Performance Evaluation of ANFIS model}

The prediction performance of ANFIS model will be measured by comparing the predicted values with actual values from laboratory results. The error is calculated by using RMSE, $R, R^{2}$ and $\bar{R}^{2}$. RMSE, $R, R^{2}$ and $\bar{R}^{2}$ evaluation criterion are applied in comparing the performance of ANFIS and Linear Regression models.

Root mean square error (RMSE) measures how precisely the ANFIS models predict the target. RMSE is calculated using

$$
\operatorname{RMSE}=\sqrt{\frac{1}{N} \sum_{t=1}^{N}\left(A_{t}-F_{t}\right)^{2}}
$$

where $A_{t}$ and $F_{t}$ are actual and fitted values, respectively and $\mathrm{N}$ is the number of training or testing sample [22].

The model fitting is measured using the correlation coefficient ( $R$ ):

$$
R=\frac{\sum_{t=1}^{N}\left(A_{t}-\bar{A}\right)\left(F_{t}-\bar{F}\right)}{\sqrt{\sum_{t=1}^{N}\left(A_{t}-\bar{A}\right)^{2} \cdot \sum_{t=1}^{N}\left(F_{t}-\bar{F}\right)^{2}}}
$$

where $A_{t}$ and $F_{t}$ are actual and predicted values, $N$ is number of training and testing data set, $\bar{A}=\frac{1}{N} \sum_{t=1}^{N} A_{t}$ and $\bar{F}=\frac{1}{N} \sum_{t=1}^{N} F_{t}$ are the average values of $A_{t}$ and $F_{t}$ over the training or testing data.

Coefficient of determination $\left(R^{2}\right)$ also known as $\mathrm{R}$-square is a measure of prediction accuracy. The range is between 0 to 1 . The closer the correlation of determination to 1 , the more accurate is the prediction since there are more variances accounted for. The formula for $R^{2}$ is given below [22].

$$
R^{2}=\left(\frac{\sum_{t=1}^{N}\left(A_{t}-\bar{A}\right)\left(F_{t}-\bar{F}\right)}{\sqrt{\sum_{t=1}^{N}\left(A_{t}-\bar{A}\right)^{2} \cdot \sum_{t=1}^{N}\left(F_{t}-\bar{F}\right)^{2}}}\right)^{2}
$$


Adjusted $\mathrm{R}$ square $\left(\bar{R}^{2}\right)$ is used as a guard against over fitting of linear regression model. Usually, the values of $\bar{R}^{2}$ will be equal to or less than $R^{2}$. If the values of $R^{2}$ and $\bar{R}^{2}$ differ radically (i.e. more than 1 ), there is a possibility that the model has been over fitted. Meaning that, adding new variables does not contribute to fit the model [23].

The formula of $\bar{R}^{2}$ is as follow:

$$
\bar{R}^{2}=1-\frac{n-1}{n-k-1}\left(1-R^{2}\right)
$$

where $n$ is the number of training and testing data sets, $k$ is the number of independent variables and $R^{2}$ is the coefficient of determination.

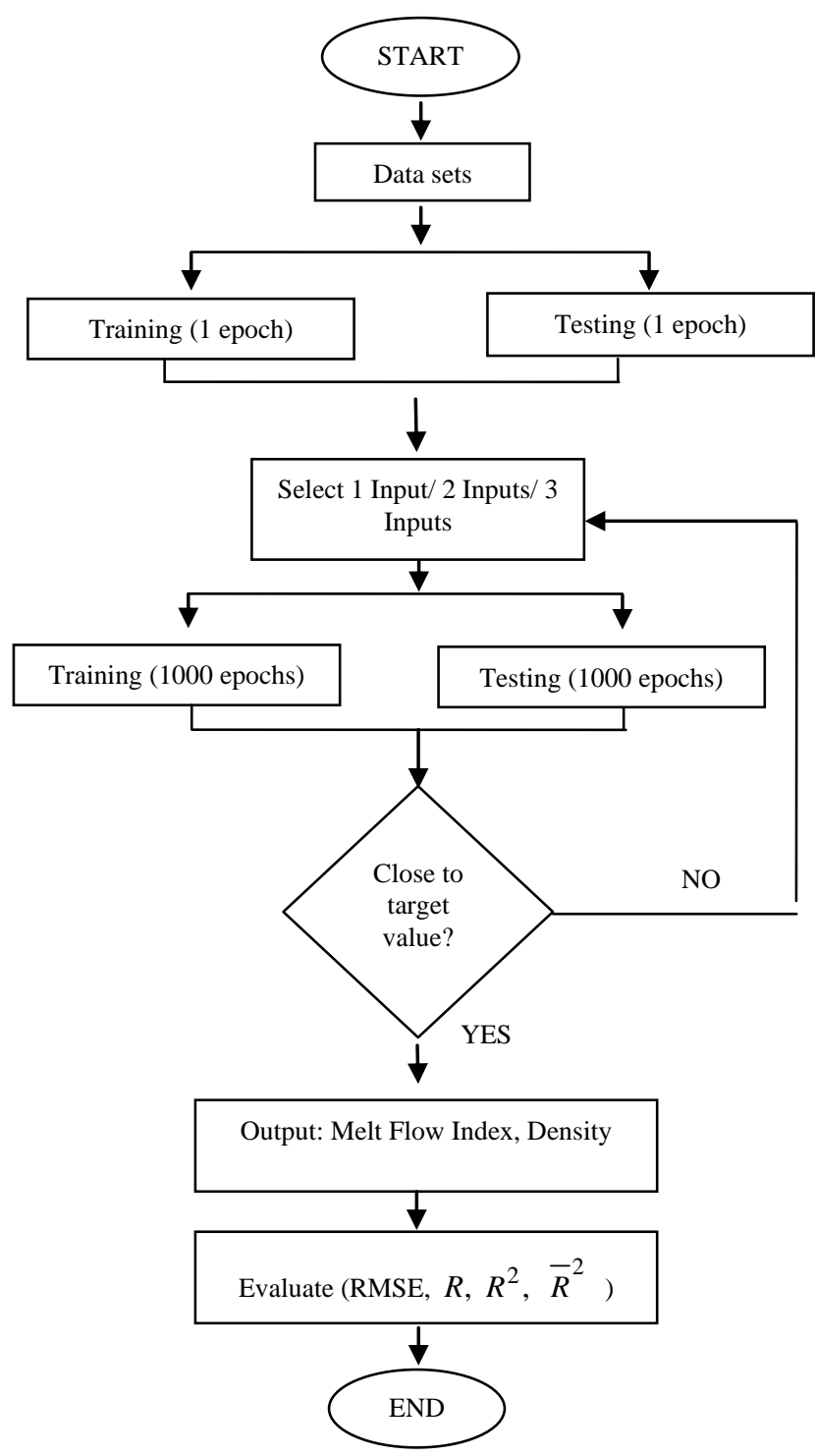

Fig. 1. Summary of ANFIS model.

\section{Development of ANFIS Model}

The process of developing ANFIS model starts by dividing data set into training set (odd-indexed samples) and checking set (even-indexed samples) with the ratio of 50\%-50\%. Then, to identify the best ANFIS model, only one epoch is used to train the training data set. The best ANFIS model here is referred to as the model with selected components that have the potential to give a high accuracy in predicting physical properties of degradable composites. The model with the smallest of RMSE of training error will be chosen as the best ANFIS model. In this research, the ANFIS model with various combination of components are trained with one epoch using a hybrid learning rule. According to [18], a single epoch is good enough to tell us how well the ANFIS model will perform after further training. Selection of component is based on the assumption that the ANFIS model with the smallest RMSE values after one epoch of training is sufficient for achieving the smallest RMSE values [5]. A hybrid learning rule is used to train the data set.

After the best ANFIS model is identified, that best ANFIS model will be trained again but for one thousand epochs. For the 1-Input model, there are four ANFIS models $\left(C_{1}^{4}=4\right)$. Out of the four models, the model with the smallest RMSE of training will be chosen. The same process is applied in choosing the best model for the 2-Input, 3-Input and 4-Input ANFIS models. For the 2-Input model there are six ANFIS models ( $C_{2}^{4}=6$ ), for the 3 -Input model there are four ANFIS models $\left(C_{3}^{4}=4\right)$ and for the 4-Input model there is only one ANFIS model $\left(C_{4}^{4}=1\right)$. After one thousand epochs of training, again the percentage error of the RMSE is recorded.

In the final phase, the prediction ability of ANFIS model is assessed. Root mean square error (RMSE), correlation coefficient ( $R$ ), coefficient of determination $\left(R^{2}\right)$ and adjusted $\mathrm{R}$ square $\left(\bar{R}^{2}\right)$ are used to evaluate the error in the prediction outcome. The process of developing ANFIS model is summarized as illustrated in Fig. 1.

\section{RESULTS}

Table I indicates that, starch is found to be the best predictor for 1-Input set in predicting the physical properties of degradable composites. The combination of PE and OPB is the better predictor set when compared to the other 2-Input sets. For 3-Input predictor set, no significant difference was found between PE, OPB, PO combination or PE, OPB, starch combination or PE, PO, starch combination. Thus, any of these three combinations can be used in predicting the physical properties of degradable composites. Nevertheless PO, OPB, starch combination without the major component (synthetic plastics) will not produce high quality degradable composites [18]. In this research, the composition of PE, OPB and PO was used to predict the physical properties of degradable composites. For 4-Input predictor set, the data set are trained with one thousand epochs without being trained with one epoch. This is because all inputs are used to predict melt flow index and density of degradable composites.

Table II presents the RMSE of training and testing errors of the best ANFIS model for one thousand epochs for melt flow index and density prediction. The table indicates that, the best predictor for 1-Input, 2-Input, 3-Input and 4-Input set are found to have the smallest RMSE of testing error for the prediction of melt flow index and density. 
TABLE I: RMSE VALUES OF 1-INPUT, 2-INPUT AND 3-INPUT ANFIS MODEL FOR THE PREDICTION OF MELT FLOW INDEX AND DENSITY WITH 1 EPOCH

\begin{tabular}{lcccc}
\hline \hline \multirow{2}{*}{ INPUT } & \multicolumn{2}{c}{ RMSE } & \multicolumn{2}{c}{ RMSE } \\
\cline { 2 - 5 } & MELT FLOW INDEX & \multicolumn{1}{c}{ DENSITY } \\
\cline { 2 - 5 } & TRAIN & TEST & TRAIN & TEST \\
\hline STARCH & 0.0250 & 0.0260 & 0.0187 & 0.0184 \\
\hline PE,OPB & 0.0050 & 0.0049 & 0.0056 & 0.0055 \\
\hline PE,OPB,PO & 0.0030 & 0.0030 & 0.0043 & 0.0044 \\
\hline PE,OPB,STARCH & 0.0030 & 0.0030 & 0.0043 & 0.0044 \\
\hline PE,PO,STARCH & 0.0030 & 0.0030 & 0.0043 & 0.0044 \\
\hline PO,OPB,STARCH & 0.0030 & 0.0030 & 0.0043 & 0.0044 \\
\hline \hline
\end{tabular}

TABLE II: RMSE VALUES OF ANFIS MODEL FOR DIFFERENT INPUT SELECTION FOR THE PREDICTION OF MELT FlOW INDEX AND DENSITY WITH 1000 EPOCHS

\begin{tabular}{llccc}
\hline \multirow{3}{*}{ INPUT } & \multicolumn{2}{c}{ RMSE } & \multicolumn{2}{c}{ RMSE } \\
\cline { 2 - 5 } & MELT FLOW INDEX & \multicolumn{2}{c}{ DENSITY } \\
\cline { 2 - 5 } & TRAIN & TEST & TRAIN & TEST \\
\hline STARCH & 0.0250 & 0.0260 & 0.0187 & 0.0184 \\
\hline PE,OPB & 0.0030 & 0.0030 & 0.0043 & 0.0044 \\
\hline PE,OPB,PO & 0.0030 & 0.0030 & 0.0043 & 0.0044 \\
\hline PE,OPB,PO,STARCH & 0.0030 & 0.0030 & 0.0043 & 0.0044 \\
\hline \hline
\end{tabular}

TABLE III: $R, R^{2}, \bar{R}^{2}$ VALUES OF 1-INPUT, 2-INPUT, 3-INPUT AND 4-INPUT ANFIS MODEL FOR THE PREDICTION OF MELT FLOW INDEX AND DENSITY

\begin{tabular}{lcccccc}
\hline \hline & \multicolumn{3}{c}{ MELT FLOW INDEX } & \multicolumn{3}{c}{ DENSITY } \\
\cline { 2 - 7 } INPUT & $R$ & $R^{2}$ & $\bar{R}^{2}$ & $R$ & $R^{2}$ & $\bar{R}^{2}$ \\
\hline STARCH & 0.9384 & 0.8806 & 0.8795 & 0.9192 & 0.8449 & 0.8434 \\
\hline PE,OPB & 0.9992 & 0.9984 & 0.9984 & 0.9956 & 0.9912 & 0.9911 \\
\hline $\begin{array}{l}\text { PE,OPB, } \\
\text { PO }\end{array}$ & 0.9992 & 0.9984 & 0.9984 & 0.9956 & 0.9912 & 0.9910 \\
\hline $\begin{array}{l}\text { PE,OPB, } \\
\text { PO, } \\
\text { STARCH }\end{array}$ & 0.9992 & 0.9984 & 0.9984 & 0.9956 & 0.9912 & 0.9910 \\
\hline \hline
\end{tabular}

TABLE IV: MELT FLOW INDEX AND DENSITY OF DEGRADABLE COMPOSITES FORMED BY DIFFERENT COMBINATIONS OF INPUT VARIABLES

\begin{tabular}{|c|c|c|c|c|c|}
\hline \multirow[t]{2}{*}{$\begin{array}{c}\text { INPUT } \\
\text { Combination } \\
\end{array}$} & \multirow[t]{2}{*}{$\begin{array}{c}\text { Percentage of } \\
\text { each INPUT }\end{array}$} & \multicolumn{2}{|c|}{$\begin{array}{l}\text { Melt Flow Index } \\
(\mathrm{g} / 10 \mathrm{~min})\end{array}$} & \multicolumn{2}{|c|}{ Density $\left(\mathrm{g} / \mathrm{cm}^{3}\right.$} \\
\hline & & ANFIS & LR & ANFIS & LR \\
\hline \multirow{3}{*}{ PE, OPB } & $90 \%+10 \%$ & 0.09 & 0.09 & 0.90 & 0.92 \\
\hline & $85 \%+15 \%$ & 0.09 & 0.08 & 0.90 & 0.92 \\
\hline & $100 \%+0 \%$ & 0.08 & 0.10 & 0.95 & 0.92 \\
\hline \multirow{3}{*}{ PE,OPB,PO } & $\begin{array}{c}70 \%+20 \%+ \\
10 \% \\
\end{array}$ & 0.13 & 0.13 & 0.94 & 0.90 \\
\hline & $\begin{array}{c}75 \%+25 \%+ \\
0 \% \\
\end{array}$ & 0.06 & 0.07 & 0.43 & 0.92 \\
\hline & $\begin{array}{c}90 \%+0 \%+ \\
10 \%\end{array}$ & 0.45 & 0.16 & 1.03 & 0.90 \\
\hline \multirow{3}{*}{$\begin{array}{l}\text { PE,OPB,PO, } \\
\text { STARCH }\end{array}$} & $\begin{array}{c}65 \%+15 \%+ \\
10 \%+10 \%\end{array}$ & 0.15 & 0.21 & 0.830 & 0.87 \\
\hline & $\begin{array}{c}60 \%+25 \%+ \\
10 \%+5 \% \\
\end{array}$ & 0.08 & 0.16 & 0.747 & 0.89 \\
\hline & $\begin{array}{c}65 \%+5 \%+ \\
10 \%+20 \%\end{array}$ & 0.62 & 0.29 & 0.480 & 0.84 \\
\hline
\end{tabular}

Table III shows that all input selection of ANFIS model give small RMSE values and higher values of $R, R^{2}$ and $\bar{R}^{2}$ indicate that ANFIS model has high capability to identify relevant input variables in the prediction of physical properties of degradable composites. Very high $R$ and $R^{2}$ values indicate good model fitting of the ANFIS model developed. The findings also showed that, the difference between $R$ and $\bar{R}^{2}$ values is small which indicates that the addition of new variable does not contribute to the over fitting of ANFIS model.

The ANFIS model developed in this research are ready to be used in identifying the physical properties of degradable composites produced using different combination of input variables. Table IV shows several combinations of input sets that produce different physical characteristics of degradable composites. Other combinations could also be predicted using the developed ANFIS and Liner Regression (LR) models to suit the needs of the polymer industry in producing degradable composites.

\section{CONCLUSION}

In this study, role of input selection in prediction of physical properties of degradable composites using ANFIS has been done. Starch is found to be the best predictor for 1-Input predictor set, the combination of PE and OPB is the better predictor for 2-Input predictor set. However for 3-Input predictor set, no significant difference was found between PE, OPB, PO combination or PE, OPB, starch combination or PE, PO, starch combination. Thus, any of these three combinations can be used in predicting the physical properties of degradable composites. Finally a 4-Input predictor set of ANFIS model comprising of PE, PO, OPB and starch was also found to give high prediction accuracy for all the two physical properties of degradable composites under studied as reflected by the small RMSE values, high $R$ and $R^{2}$ values. These show that, ANFIS model has high capability to identify relevant input variables in the prediction of physical properties of degradable composites. It is also recommended that further research be carried out on other aspects of degradable composites using modified ANFIS. The findings of this research will certainly benefit the industry related to biopolymer products.

\section{REFERENCES}

[1] E. H. Kadi and A. Y. Assaf, "Prediction of the fatigue life of unidirectional glass fiber/epoxy composite laminae using different neural network paradigms," Composite Structures, vol. 55, pp. 239-246, 2002.

[2] Zaheeruddin and Garima, "A neuro-fuzzy approach for prediction of human work efficiency in noisy environment," Applied Soft Computing, vol. 6, pp. 283-294, 2006.

[3] M. A Jarrah, A. Y. Assaf, and E. H. Kadi, "Neuro-fuzzy modeling of fatigue life prediction of unidirectional glass fiber/epoxy composite laminates," Journal of Composite Materials, vol. 36, no. 6, pp. 685-700, 2002.

[4] S. Y. Lee, M. A. Hanna, and D. D. Jones, An Adaptive Neuro-Fuzzy Inference System for Modeling Mechanical Properties of Tapioca Starch-Poly (Lactic Acid) Nanocomposite Foams, Published in Starch/ Starke, vol. 60, pp. 159-164, 2008.

[5] J. S. R. Jang, "ANFIS: Adaptive-network-based fuzzy inference system," IEEE Transactions on Systems, Man, and Cybernetics, vol. 23, no. 3, pp. 665-684, 1993.

[6] D. K. Pratihar, "Soft computing," Alpha Science International Ltd, 2008, pp. 82.

[7] J. Galindo, A. Urrutia, and M. Piatinni, Fuzzy Databases Modeling, Design and Implementation, Idea Group Publishing, 2006. 
[8] G. J. Klir, U. S. Clair, and B. Yuan, Fuzzy Set Theory: Foundation and Applications, Prentice Hall PTR, 1997.

[9] I. B. Topcu and M. Saridemir, "Prediction of rubberized concrete properties using artificial neural network and fuzzy logic," Construction and Building Materials, vol. 22, pp. 532-540, 2008.

[10] S. A. Oke, A. O. Johnson, I. O. Popoola, O. E. Owaba, and F. A. Oyawale, "Application of fuzzy logic concept to profitability quantification in plastic recycling," The Pacific journal of Science and Technology, vol. 7, no. 2, pp. 163-174, 2006.

[11] H. I. Kadi, "Modeling the mechanical behavior of fiber-reinforced polymeric composite materials using artificial neural networks - A review," Composite Structures, vol. 73, pp. 1-23, 2006.

[12] Z. Zhang and K. Friedrich, "Artificial neural networks applied to polymer composites: a review," Composite Science and Technology, vol. 63, pp. 2029-2044, 2003

[13] L. S. Admuthe and S. Apte, "Adaptive neuro-fuzzy inference system with subtractive clustering: A model to predict fiber and yarn relationship," Textile Research Journal, vol. 80, no. 9, pp. 841-846, 2010.

[14] M. Wei, B. Bai, A. H. Sung, Q. Liu, J. Wang, and M. E. Cather, "Predicting injection profiles using ANFIS," Information Sciences, vol. 177, pp. 4445-4461, 2007.

[15] S. Y. Lee, M. A. Hanna, and D. D. Jones, An Adaptive Neuro-Fuzzy Inference System for Modeling Mechanical Properties of Tapioca Starch-Poly (Lactic Acid) Nanocomposite Foams, Published in Starch/ Starke, vol. 60, pp. 159-164, 2008.

[16] M. A. Jarrah, Y. A. Assaf, and H. E. Kadi, "Neuro-fuzzy modeling of fatigue life prediction of unidirectional glass fiber/epoxy composite laminates," Journal of Composite Materials, vol. 36, no. 6, pp. 685-700, 2002.

[17] A. Y. Assaf and E. H. Kadi, "Fatigue life prediction of unidirectional glass fiber/epoxy composite laminae using neural networks," Composite Structures, vol. 53, pp. 65-71, 2001.

[18] J. S. R. Jang and C. T. Sun, Neuro-Fuzzy and Soft Computing: A Computational Approach to Learning and Machine Intelligence, 1st ed., USA: Prentice-Hall, 1997, ch. 16, p. 434.

[19] R. Sindelar and R. Babuska, "Input selection for nonlinear regression models," IEEE Transactions on Fuzzy Systems, vol. 12, no. 5, pp. 688-696, 2004

[20] S. L. Chiu, "Selecting input variables for fuzzy models," Journal of Intelligent and Fuzzy Systems, vo. 14, no. 4, pp. 243-256, 1996.
[21] Z. Zhang, P. Klein, and K. Friedrich, "Dynamic mechanical properties of PTFE based short carbon fibre reinforced composites: experiment and artificial neural network prediction," Composites Science and Technology, vol. 62, pp. 1001-1009, 2002.

[22] Y. M. Wang and T. M. S. Elhag, "An adaptive neuro- fuzzy inference system for bridge risk assessment," Journal of Expert Systems with Applications, vol. 32, pp. 336-348, 2007.

[23] C. Montgomery, D. Peck, and A. Elizabeth, Introduction to Linear Regression Analysis, $2^{\text {nd }}$ ed., USA: A Wiley-Interscience publication, 1992.

Syamsiah Abu Bakar is currently works as a mathematics lecturer in University Kuala Lumpur Malaysia France Institute, Malaysia. She received master of science degree in mathematics from University Technology Mara, Malaysia in 2011. Her research interests include fuzzy decision making, neural networks and degradable plastics.

Rosma Mohd Dom is currently works as a mathematics lecturer in University Technology Mara, Malaysia. She received master of science degree in mathematics from Indiana University, Bloomington, USA in 2009. She received $\mathrm{PhD}$ degree in medical informatics University Malaya, Malaysia in 1987. Her research interests include predictive data mining, medical informatics and fuzzy decision making.

Ajab Bai Akbarally is currently works as a mathematics lecturer in University Technology Mara, Malaysia. She received master of science degree in pure mathematics from University Kebangsaan Malaysia, Malaysia in 2001. She received $\mathrm{PhD}$ degree in pure mathematics University Kebangsaan Malaysia, Malaysia in 2008. Her research interests include complex analysis and geometric function theory.

Wan Hasamudin Wan Hassan is currently works as a group leader, Bio-composite Group, Malaysia Palm Oil Board. His research interests include extraction of xylose and cellulose from oil palm biomass, enzymatic treatment of oil palm biomass, bio-degradable plastic from oil palm biomass, particleboard technology, chemical analysis and analytical technology and biopolymer technology. 